\author{
Interview
}

\title{
SPINOZA'S ONGEHOORZAAMHEID. EEN GESPREK MET JONATHAN ISRAEL
}

\author{
Sonja Lavaert
}

Spinoza was de eerste filosoof die systematisch de voordelen van democratie, individuele vrijheid en gelijkheid bepleitte als basis van een seculiere sociale en ethische theorie. ${ }^{1}$ Samen met een kleine groep van denkers legde de Hollandse filosoof in de $17^{\text {de }}$ eeuw de grondslag van een radicale verlichting die democraten en vrijdenkers een eeuw later zouden realiseren in de Franse revolutie. Dit is een notendop de these die Jonathan Israel uitvoerig argumenteert in de om en bij 3000 bladzijden van zijn drie delen tellende monumentale werk over de verlichting dat met Democratic Enlightenment voorlopig wordt afgesloten. ${ }^{2}$ Het begon toen de Britse historicus in Radical Enlightenment van 2001 een studie maakte over Spinoza en de denkers uit diens omgeving. ${ }^{3}$ Tijdens zijn onderzoek naar de Hollandse republiek - in het decennium daarvoor verrichte Israel baanbrekend historisch werk over de republiek - was hij geinntrigeerd geraakt door de storm van heftige reacties, de ophef en de historische wending die het gedachtegoed van deze club bleek te bewerkstellingen. Spinoza en zijn vrienden brachten de idee op gang dat het doel van politiek erin bestaat het leven goed te maken voor iedereen en dat ieders belang gelijkwaardig is. Dit doel kon slechts worden gerealiseerd door de afschaffing van religieuze autoriteit, de volledige vrijheid van denken en meningsuiting en de beslissingsmacht bij het volk. Een politiek radicale stelling waarvan Israel meent dat ze doorwerkte tot in de Franse revolutie. Dus zette hij zijn onderzoek verder: eerst in Enlightenment Contested waar hij zich boog over de eerste helft van de $18^{\text {de }}$ eeuw, nu in Democratic Enlightenment waar hij in detail de aanloop naar en het begin van de revolutie volgt. Het zijn de ideeën van radicale filosofen, zoals Diderot die in het voetspoor van Spinoza de samenleving helemaal en grondig wilden veranderen, niet de gematigde van de meer bekende verlichtingsfilosofen zoals Locke, Hume, Voltaire of zelfs Rousseau, die zijn gerealiseerd in de eerste jaren van de Franse Revolutie. In kringen van historici is het uitermate controversieel te beweren dat een historische wending wordt voltrokken door filosofieën en een revolutie veroorzaakt door (alleen maar) ideeën. Het blijft moeilijk om wat uiteindelijk een filosofische stelling is 'wetenschappelijk' te bewijzen - misschien kan dat alleen filosofisch? - maar het is een feit dat Israel een indrukwekkende 
hoeveelheid boeiend tekstmateriaal met elkaar in verband brengt, terecht de aandacht vestigt op minder bekende auteurs, het onderzoek daarmee ten zeerste verrijkt en bijdraagt tot de vernieuwing van de belangstelling voor de verlichting, politieke filosofie en Spinoza. We hebben een gesprek over zijn boek, de philosophes, de rede, en uiteraard over Spinoza, democratie en revolutie. Op mijn vragen antwoordt hij genuanceerd, bescheiden, geduldig, vaak schaterlachend, nieuwsgierig naar de hem minder bekende auteurs of hun kritiek op zijn werk, begaan met de wereld, enthousiast liefhebberend in ideeën en filosofie. Jonathan Israel houdt van intellectuele controverses maar kan ik hem ook verleiden tot controversiële uitspraken?

In de drie delen van uw werk, ook in het laatste, maakt u een onderscheid tussen een gematigde en een radicale verlichting; het zouden de radicale ideeën zijn die

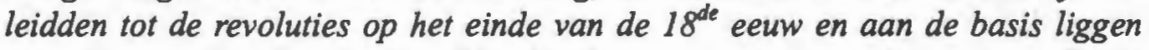
van de actuele democratie. Het breekpunt tussen gematigde en radicale verlichting, en des te meer met de antiverlichtingsdenkers, is de houding tegenover religie, het atheïme. Is atheisme een voorwaarde voor democratie?

Neen, natuurlijk niet. Democratie is een poging om vrijheid van geloof, denken en uitdrukking te garanderen voor iedereen. Zeggen hoe mensen moeten denken zou juist in strijd zijn met democratie. Ik denk niet dat Spinoza ooit heeft gedacht dat de meerderheid van de mensen atheïst zou worden en er zijn ook in onze tijd geen tekenen die wijzen in de richting van een grote toename van atheïsme. Hoe zou het dan een voorwaarde kunnen zijn? Het heeft geen zin dit te stellen. In de $18^{\mathrm{de}}$ eeuw waren het vaak gelovigen die de idealen van de revolutie omhelsden; zij zagen het democratisch gedachtengoed als een erfenis van hun christelijk geloof. Ook zo in Spinoza's omgeving had je figuren zoals Jarig Jelles die vanuit hun religieuze overtuiging aansloten bij zijn verlichte denken.

Anderzijds is het toch wel de vraag of iemand die uitgaat van een religieus standpunt echt kan geëngageerd zijn in democratie. Mij komt het voor dat gelovigen die kozen voor de verlichting, zoals bijvoorbeeld de Unitariens, doorgaans gelovigen waren die zich verzetten tegen elke vorm van institutionalisering van hun geloof. Op het eerste gezicht lijkt het religieuze perspectief van Priestley en Jarig Jelles in strijd met hun verlichte ideeën maar dat wordt anders wanneer je kijkt naar wat ze begrijpen onder religie, dus als je de inhoud van hun geloof van naderbij bekijkt. Je merkt dan dat democratie in feite inherent was aan hun religieus perspectief.

\section{$U$ denkt niet dat het belangrijk is atheisme te onderlijnen?}

Toch, ik denk van wel, maar in een intellectueel debat, onder filosofen die uit 
zijn op de waarheid. De meeste mensen zijn evenwel niet geïnteresseerd in de waarheid maar ze zijn wel degelijk begaan met wat er gebeurt in de maatschappij en in de wereld.

Tegenwoordig ontbreekt een goed links alternatief in Italië, Frankrijk of om het even waar. De ideeën die circuleren in linkse partijen zijn allemaal nogal ontgoochelend, maar mocht er wel een goed links bestaan, dan zou het niet zo veel bereiken door te spreken over atheïsme of religieuze kwesties. De linkse leiders zouden wellicht atheïsten zijn maar ze zouden er niet over spreken want dit is niet de goede manier om de boodschap te brengen. Ik ben niet zo radicaal als sommige anderen zijn, wat atheïsme betreft.

Hetzelfde trouwens in verband met de revolutie. De meeste van de radicale filosofen die ik bewonder, waren zeer bekommerd om het geweld dat een revolutie met zich kan meebrengen. Ze hoopten het geweld te kunnen vermijden. Geweld is iets afschuwelijk. In de eerste jaren van de Franse Revolutie, begin de jaren '90, voor de komst van de terreur en Robespierre, was het de grote trots van de revolutionairen dat ze ten opzichte van de andere - Spaanse, Engelse, Amerikaanse - revoluties die allemaal zeer gewelddadig waren, veel meer hadden bereikt - de totale afschaffing van alle feodaliteit - en dat terwijl ze de meest rationele en minst gewelddadige van alle revoluties hadden bewerkstelligd. We hebben daar nu bijna geen idee meer van door alle gewelddaden die daarna gebeurden. De minimalisatie van het geweld in de beginjaren van de Franse revolutie was een grote realisering.

Denkt u dat de ideeën van de radicale verlichting zijn gerealiseerd in de huidige westerse democratieën?

Ik ben er van overtuigd dat de Franse revolutie de basis vormt voor onze westerse democratie, wat de principes betreft. De ideeën waarvoor men streed universele mensenrechten, een maatschappij die het welzijn van de meerderheid van de mensen probeert te realiseren - vormen de onderliggende beginselen van de westerse democratieën. Althans, in Europa; in de Verenigde Staten is men meer begaan met de belangen van het individu. Het Amerikaanse congres dient eerder de belangen van grote bedrijven dan het algemeen belang. Maar toch..., de grote politieke idee van de radicale verlichting is de volkssoevereiniteit, wat wil zeggen dat het de plicht is van een regering om de algemene wil te realiseren. We hebben de volkssoevereiniteit niet enkel aan Rousseau te danken; in de $18^{\text {de }}$ eeuw waren een hoop denkers van oordeel dat politiek wordt bedreven in het belang van het volk in het algemeen. En de moderne democratieën hebben deze traditie en principes geërfd, helaas zonder er zich bewust van te zijn. Ze kennen hun intellectuele bronnen niet, kennen niet hun eigen familiegeschiedenis. De 
historici hebben hier veel te weinig onderzoek naar gedaan en er onvoldoende over nagedacht. De republiek is de wil van het volk en moet tegemoet komen aan de belangen van het volk gezien als een geheel: dit is de grote idee van de $18^{\mathrm{de}}$ eeuw. De moderne democratieën hebben deze principes geërfd maar of ze er ook naar leven, is weer een andere zaak.

Dat zou er kunnen op wijzen dat het eerder de gematigde verlichtingsideeën zijn in de plaats van de radicale die zich hebben gerealiseerd in de huidige democratieën. Is vandaag een radicale verlichting niet nog steeds subversief? Zo denken wellicht actuele radicale filosofen zoals Antonio Negri.

Ik ben het daar helemaal mee eens. Vooral in de Verenigde Staten, maar ook in Europa, overal in feite. We hebben nergens een democratie die de radicale vrijheid van uitdrukking, geloof en denken heeft gerealiseerd. Radicale verlichting is vandaag nog steeds subversief, overal.

\section{Hebben we dan niet nog steeds een revolutie nodig?}

Een revolutie is nodig in de zin dat het denken en de instellingen dienen te veranderen. Ik heb het echter moeilijk met mensen die de rol van Rousseau overschatten zoals naar mijn mening Negri doet, en die teruggaan op een heel specifieke interpretatie van verlichting en volkssoevereiniteit zoals je ook al zag bij Babeuf. De manier waarop de echte revolutionaire intellectuelen spraken, zijn we helemaal kwijt. Babeuf, zoals Negri vandaag, vond de vertegenwoordigende democratie corrupt omdat ze niet de wil van het volk vertegenwoordigde en dus verwierp hij de democratie. Hij riep de menigte op tot een nieuwe revolutie, tot samenzwering en geweld. Daarvoor werd Babeuf dan ook veroordeeld. De Grondwet van 1793 was democratisch maar niet geïmplementeerd. De Grondwet van 1795 daarentegen was niet democratisch maar wel geïmplementeerd. Enkelingen controleerden de regering die zich een republiek gebaseerd op vertegenwoordiging noemde. Veel van de intellectuelen, zoals bijvoorbeeld Benjamin Constant die pas later liberaal werd, als jongeman was hij veel radicaler, of Brissot zeiden terecht: je moet de regering steunen in dergelijke omstandigheden want volkse opstanden zullen niet evolueren in de goede richting. Een omwenteling moet worden voltrokken door een kleine groep van mensen die werken op een manier zoals men deed in de eerste jaren na 1789. De universele mensenrechten, de afschaffing van feodaliteit en slavernij, de emancipatie van de joden en al de positieve dingen die in het begin werden gerealiseerd, waren niet een realisatie van de menigte. Ik ben het wat dit betreft niet eens met Negri. Deze dingen kwamen uit de filosofie, niet uit de volkse wil.

Robespierre zei: weg met de filosofie, dit is een zaak van de gewone mensen, en 
ik vertegenwoordig, meer dan anderen, de gewone mensen. Dat is zeer gevaarlijk en ook verkeerd. Robespierre kon hiermee het volk voor zich winnen maar het was volgens mij verkeerd. Het klinkt revolutionair de sansculottes te mobiliseren, maar in feite is het contrarevolutionair. De sansculottes vernietigden de revolutie.

Uw interpretatie van Spinoza als immanent denker en materialist is in overeenstemming met de marxistische Franse interpretaties van de jaren '70 zoals van Matheron of Macheray. Dus ook met de interpretatie van Negri, denk ik dan.

Ik ben het eens met Negri's interpretatie van Spinoza maar niet met zijn interpretatie van de menigte in Spinoza's werk: de menigte krijgt geen positieve rol toebedeeld door Spinoza. Natururlijk was Spinoza een revolutionaire denker, maar niet op de manier zoals Negri dat ziet. Alles heeft te maken met rationaliteit. Spinoza dacht dat de maatschappij beter werd naarmate ze rationeler werd. Negri denkt in een totaal andere richting. Subversieve acties in het teken van een verbetering van de maatschappij gebeurden in de Franse revolutie door een kleine groep mensen, filosofen, die de maatschappij in een welbepaalde richting wilden veranderen. Spinoza's subversie bestond in de creatie van een soort ondergrondse elite, te vergelijken met de Illuminati in de $18^{\mathrm{de}}$ eeuw, een beweging van een kleine groep mensen die zich bezighielden met filosofie en probeerden in sleutelposities terecht te komen om van binnenuit dingen te veranderen. Dit is een model van subversie dat niet afhangt van de menigte. De zaken gaan erop vooruit wanneer ze rationeler worden maar de menigte kan niet rationeler worden. Een maatschappelijke revolutie is nodig 'voor' de mensen maar ze kan niet voltrokken worden 'door' de mensen: dit is het punt waarop ik het niet eens ben met Negri.

Is dit niet het probleem van elke overgang? Hoe vertaal je radicaal nieuwe ideeën in instellingen?

Bij Spinoza is het een filosofische kwestie. De maatschappij moet op een meer rationele basis worden georganiseerd. Hoe rationeler mensen zijn, hoe beter ze kunnen samenwerken, delen, overleggen, compromissen sluiten, belangen laten samenvallen, et cetera. In het algemeen zijn mensen echter niet zo rationeel: ze hebben vooroordelen, zitten vol ressentiment en wrok, zijn afgunstig, haatdragend en jaloers... en daarom is er ook zo'n sterke tendens tot achteruitgang en verslechtering van de toestand. Als dingen beter gaan, hebben we dat zeker niet te danken aan de menigte. Dit is de les van Spinoza en die is moeilijk in overeenstemming te brengen met de interpretatie van Negri. 
Is de eis van rationaliteit niet in strijd met realisme? Dingen werken niet zo, $u$ zegt het zelf. Hoe kan een politiek systeem, gebaseerd op rationaliteit,worden gerealiseerd?

Zoals in de Franse revolutie, daar gebeurde dat. Dit is geen inbeelding, het gebeurde echt, het is een feit. Dit is ook de reden waarom ik een intellectuele geschiedenis van de Franse revolutie aan het schrijven ben, want ik meen dat het concept van radicale verlichting een betere manier is om de revolutie te verklaren. De groep filosofen en journalisten, Condorcet, Brissot, et cetera., ook Babeuf wat dit betreft, Marat niet, hij uitgezonderd, maar verder al die journalisten die de revolutie ondersteunden tussen 1789 en 1793, allemaal waren ze voor echte persvrijheid. Dit is het enige voorbeeld in de geschiedenis van een echte vrijheid van meningsuiting. Het was niet zoals in Rusland waar alle vrijheid van uitdrukking meteen werd opgeheven. In die beginjaren ' 90 verschenen kranten die tegen elke verandering waren, de meest reactionaire verdedigingen van het Ancien Régime werden gepubliceerd. De royalistische Gazette de Paris verscheen tot 1792. Als men over persvrijheid sprak, dan was dit echt waar. Deze revolutionaire vrijheid was te danken aan twintig à dertig mensen in de Assemblée Nationale op wie alles steunde, een kleine groep van intellectuelen die voor geen enkele sociale klasse representatief waren. De marxisten zeggen altijd: er waren geen boeren en arbeiders vertegenwoordigd in de Assemblée Nationale. Dat is waar, maar wat ze vergeten is dat er ook geen bankiers, handelaren of zakenmensen waren... De Assemblée Nationale bestond uit journalisten, advocaten, intellectuelen, een elite met andere woorden, maar wel een elite die democratisch was verkozen. Advocaten vormden de grootste groep maar zij waren niet de belangrijke figuren. De echt belangrijke figuren waren een heel kleine groep intellectuelen die ijverden voor mensenrechten, voor de afschaffing van feodalisme, titels en slavernij, en zich keerden tegen elke vorm van discriminatie: van joden, zwarte mensen, vrouwen. Het gaat altijd over dezelfde kleine groep, Condorcet, Sieyès, Volney, Mirabeau, ... niet meer dan dertig mensen die totaal niet representatief waren voor de grote sociale blokken.

In uw werk keert $u$ zich expliciet af van de postmoderne kritiek op de verlichting. $U$ kunt evenwel toch niet ontkennen dat er een spanning bestaat tussen de universalistische idee van gelijkheid en van één mensheid enerzijds en de verschillen anderzijds. Negri en andere radicale denkers zoals Michael Hardt, die ook uitgaan van de gelijkheidsgedachte en ijveren voor algemene mensenrechten, vervangen het problematische universalisme door de notie van common. Hoe gaat u met die spanning om? Of anders gezegd, hoe verbindt $u$ universalisme met politieke vrijheid en met het bestaan van verschillen? En met vrijheid van uitdrukking? 
Ik denk dat er een spanning móet zijn tussen universalisme en vrijheid van uitdrukking want iedereen wil iets anders. Vrijheid voor iedereen kan niet anders dan een spanning creëren want je wil tegemoet komen aan iedereen die elk afzonderlijk verschillende dingen wil. Ik zie de oplossing in een mix van vrijheid en beperking. Je kunt geen absolute vrijheid hebben. Van sommige mensen die gevaarlijke dingen doen, zoals de maffia, moet je overigens de vrijheid beperken. Je kunt mensen niet tegenhouden om gevaarlijke dingen te denken, maar je kunt en moet ze wel tegenhouden om gevaarlijke dingen te doen want je moet de rest van de maatschappij beschermen. In de mate dat hij een spanning erkent tussen gelijkheid en vrijheid en bekommerd is om alle mensen, denk ik dat ik dichter sta bij Negri dan bij de postmoderne filosofen, of Foucault: in zijn denken zie ik geen universalisme. Een van de grote motoren van de radicale verlichting, van Histoire philosophique des dewx Indes bijvoorbeeld, het eerste werk waar de idee als dusdanig wordt geformuleerd, is dat er één mensheid is. ${ }^{4}$ Het inzicht dat we allemaal mensen zijn is een mijlpaal in het denken van de radicale verlichting.

De visie van Rousseau op volkssoevereiniteit en algemene wil verschilt levensgroot van die van Spinoza. Ze kan zelfs aanleiding geven tot onverdraagzaamheid, kwezelarij, racisme, militant patriottisme...

Ze kan niet alleen, ze gaf daadwerkelijk aanleiding tot dit soort zaken. Van zodra Robespierre het overnam, kreeg je dat chauvinisme en de vreemdelingenhaat die er voorheen helemaal niet waren.

In verband met Rousseau heeft $u$ het over de 'heiligheid'van het recht en de gehoorzaamheid aan de wetten. Die woorden deden me denken aan de kritiek van de Italiaanse filosoof Paolo Virno. Deze actuele radicale denker interpreteert Spinoza als een kritiek op en omkering van de visie van Hobbes, en hij doet dat op basis van het gebruik van de concepten volk en menigte. Voor Hobbes moest de menigte worden omgevormd tot een gehoorzaam, volgzaam en stilzwijgend volk. Zou men kunnen zeggen dat Rousseau Hobbes herhaalt, terwijl Diderot aansluit bij Spinoza?

Ik denk dat Diderot inderdaad aansluit bij Spinoza, en ik vind ook dat filosofen en historici zich veel meer bewust moeten worden van de samengestelde natuur van het concept 'algemene wil'. De algemene wil is een zeer complex begrip in de revolutie, een begrip dat we overigens helemaal niet te danken hebben aan Rousseau, ook al wordt hij er doorgaans mee geassocieerd en werd hij ook tijdens de revolutie veel vaker dan anderen vermeld. Hij was het bekendst, de meest aanvaarde naam maar tezelfdertijd was iedereen kritisch tegenover zijn visie. Tot zover zijn we het eens, de algemene wil is complex, maar ik denk dat Hobbes' idee toch helemaal iets anders is dan dat van Rousseau. Soevereiniteit 
voor Hobbes is niet bij het volk maar bij een koning. Hobbes ziet de noodzaak om de menigte te vervangen door een verenigd volk dat achter één principe staat - akkoord - maar dat één principe is een koning. Bij Rousseau is dat niet een koning.

Ziet u geen verschil tussen volk en menigte?

Ik zie vooral het verschil tussen Rousseau en Hobbes. Voor Hobbes wordt vrede gegarandeerd door de soeverein, iemand die buiten het volk staat, terwijl Rousseau de algemene wil zoekt als uitdrukking van het volk, dus binnen het volk. Rousseau denkt intern en actief, en volgt Hobbes niet. Rousseau las daarentegen wel aandachtig Spinoza maar hij spreekt er niet over want is het niet met hem eens. Volgens Maria José Villaverde zijn een aantal passages in Rousseau direct gebaseerd op Spinoza zonder dat hij er evenwel expliciet naar verwijst. ${ }^{5} \mathrm{Zij}$ beweert zelfs dat de fameuze uitspraak dat mensen moeten gedwongen worden om vrij te zijn, rechtstreeks zou ontleend zijn aan Spinoza... Ik weet niet of dit klopt. Ik heb het niet gecontroleerd, maar ik weet wel dat Rousseau een aandachtige lezer was van Spinoza, en het niet met hem eens was. Rede speelt bij Rousseau geen rol. Het is geen leidend principe. Hij is echt een filosoof van de gevoelens en emoties.

In het Theologisch-Politiek Traktaat schrijft Spinoza dat angst, religie en gehoorzaamheid een gelukkig driespan vormen, dat democratie daar weinig mee te maken heeft of zelfs het tegenovergestelde nastreeft - mensen bevrijden van angst zal vrede brengen - wat ik lees als een pleidooi voor rationaliteit, moed en ongehoorzaamheid. Gaat de discussie tussen Spinoza/Diderot en Rousseau niet over gehoorzaamheid?

Mhm...Ongehoorzaamheid tegenover wie? Toch niet tegenover de wet en de staat? Ik denk dat Spinoza subversief en ongehoorzaam is, doch niet op een gewelddadige manier. $\mathrm{Hij}$ is niet direct ongehoorzaam tegenover de wet. $\mathrm{Hij}$ is ongehoorzaam op een subtiele manier, ja en neen, misschien... Misschien is hij ongehoorzaam in een zekere zin maar je moet echt voorzichtig zijn met dit soort uitspraken. Een anarchie kan erger zijn dan om het even wat. Diderot en ook de andere revolutionaire filosofen waren zeer beducht voor de gevolgen van wetsbreuk en anarchie.

$U$ linkt ongehoorzaamheid meteen aan geweld. Bestaan er geen geweldloze revoluties?

De echte revolutie is juist geweldloos en stelt een einde aan het geweld. Geweldloze ongehoorzaamheid gaat samen met democratie. 
Om nog eens terug te komen op het materialisme en de immanente visie van Spinoza. Wat betekent dit materialisme voor uw visie op de historische realiteit?

Spinoza lezen heeft mij zeer veel geholpen en geleid tot een meer naturalistische visie op macht en religie. Religie is iets moeilijks om te begrijpen in de geschiedenis, het is een soort van mysterie. Ik denk zelfs dat het des te meer een mysterie is voor wie religieus is. Er zijn zoveel religies die gepaard gaan met zoveel conflicten. Waarom zijn er zoveel theologische en religieuze conflicten? Spinoza hielp me te begrijpen waarom religie zo belangrijk is in de traditie, waarom je in de geschiedenis zo veel vaker hiërarchische maatschappijen ziet. Ik ben als historicus altijd geboeid geweest door de omwenteling van de moderne geschiedenis, waarom men op een bepaald moment gebroken heeft met een traditie die al eeuwen meeging. Spinoza's metafysica gebaseerd op de idee van één substantie helpt om die omwenteling te verklaren. Waarom vinden mensen een maatschappelijk systeem en waarden die gedurende eeuwen werden geaccepteerd, ineens niet meer bruikbaar in de $18^{\text {de }}$ eeuw? Spinoza's materialisme kan die ommekeer verklaren.

$U$ zegt weinig over het marxisme, en als $u$ er over spreekt, is het meestal in negatieve zin. Toch is uw visie niet 20 verschillend van een historisch materialisme?

Wel, als je alle bagage van het verleden kon wegnemen en enkel een gezuiverd marxisme kon overhouden, het marxisme van de intellectuele debatten in de westerse wereld die heel interessant zijn... als je de echte betekenis van Marx' humanisme nagaat, krijg je een ander beeld dan waar het marxisme doorgaans mee wordt geassocieerd en dat is inderdaad niet zo ver bezijden mijn visie. Toch ben ik het niet eens met het economisch determinisme van Marx, dat mechanisch en reducerend is. Er is bij Marx geen materialistisch determinisme. Materialisme is volgens mij iets anders dan een benadering die alles herleidt tot economie. Uiteraard moeten we ons bewust zijn van de economische machinerie en belangen. Zoals vandaag: we moeten beseffen dat de financieel-economische groepen verantwoordelijk zijn voor deze grote crisis waar we in zijn terechtgekomen, maar ik denk niet dat deze groepen corresponderen met een klasse zoals Marx dacht. Zijn klassentheorie klopt niet. In de Verenigde Staten wordt tegenwoordig de middenklasse net zo goed uitgebuit door de grote bedrijven als de arbeidersklasse. Het gaat voor iedereen slechter. Het concept van de twee sociale basisblokken, de proletariërs en de bourgeois, is een inadequaat instrument om de historische realiteit te verklaren. Een mooi voorbeeld daarvan zien we in de Belgische revolutie van 1787-90 zoals ik ze heb beschreven in mijn boek. ${ }^{6}$ De revolutie in België toont dat Marx fout is. Men was in 
Vlaanderen, Brabant, Luik en Henegouwen helemaal niet zo tegen de aristocratie, het verhaal was helemaal anders dan in Frankrijk. Volgens mij biedt het marxisme een inadequate historische verklaring omdat het werkt met onbruikbare categorieën zoals het proletariaat en de bourgeoisie.

Wat mij boeit is hoe intellectuele controverses ook sociale fenomenen zijn, ideeën en sociale geschiedenis die samenkomen. De radicale verlichting was niet succesvoller dan de gematigde omdat ze betere ideeën had - ze hàd betere ideeën, daar niet van - wel omdat de ideeën kwamen op een moment dat de sociale noden en verzuchtingen zo hoog waren en van een aard dat het zo niet verder kon. We zijn vergeten hoe afschuwelijk de structuren en wetten waren in de $18^{\text {de }}$ eeuw. De ongelijkheid was verschrikkelijk. Het wettelijk systeem afschuwelijk. Er waren een hoop mensen die geen rechten hadden, die niet werden beschermd, vooral mensen in een ondergeschikte positie. Als een dienstmeid haar arm brak tijdens het werk, kon ze nergens terecht. Heel veel mensen hadden reden om ongelukkig te zijn. Misschien begrepen ze niet wat er fout was met de maatschappij in haar geheel maar op het moment dat de intellectuelen zeiden dat de maatschappij rot was en alles diende te veranderen, klopte dat precies met hun ervaring en dus gaven ze hun steun. We zijn het vergeten maar het Ancien Régime was een afschuwelijke maatschappij. In feite was niemand toen geïnteresseerd in de emancipatie van de joden of de afschaffing van de zwarte slavernij, tenzij de intellectuelen dan, maar dat zat mee in het pakket, een logisch pakket waarin emancipatie van joden en afschaffing van slavernij verbonden waren met andere punten die wel konden rekenen op de steun van een grote meerderheid, om allerlei soorten van redenen.

Zoals met de patriottenbeweging, de meeste mensen wisten nauwelijks waarover ze spraken en in een ideologie over democratie waren ze al helemaal niet geïnteresseerd. Maar velen hadden redenen om mistevreden te zijn, de katholieken waren het beu behandeld te worden als tweederangsburgers, en zo ontstond er steun voor de revolutie, een incoherente steun. Zo konden ideeën de motor worden van echte sociale verandering.

Doorheen uw werk legt $u$ sterk de nadruk op de samenhang van Spinoza's denken, een samenhang die uiteraard te maken heeft met zijn zijnsleer van één substantie. Ziet u die logische samenhang nog steeds gelden als iets dat nuttig is voor onze democratie vandaag? Is een zijnsleer à la Spinoza een voorwaarde voor de vorming van echte democratie?

Uiteindelijk wel, ja. Filosofisch is het monisme een voorwaarde om democratie te denken. Dat de éénsubstantieleer, radicale verlichtingsideeën en politieke democratie samenhangen wordt doorgaans niet gezien en daarom vond ik het 
belangrijk om dit te tonen. Ik heb de term 'radicale verlichting' niet uitgevonden, Margaret Jacob gebruikte de term als eerste en in de jaren ' 90 werd het een collectief onderzoek waaraan ik hoop inmiddels een bijdrage te hebben geleverd. ${ }^{7}$ Het is belangrijk te weten dat er een radicale verlichting bestaat als compleet verschillend van de gematigde verlichting. Dit is wat ik heb willen levendig maken op een directe manier - mensen bleven maar zeggen dat ik te zeer categoriseerde, de categorieën dramatiseerde - in het hoofdstuk over de aardbevingen. ${ }^{8}$ Er zijn verschillende manieren waarop mensen kijken naar de realiteit. Er bestaat geen middenpositie tussen de radicale verlichting en de conservatieve visie zoals de gematigde verlichting claimt. Óf je ziet aardbevingen als natuurkundig fenomeen dat je mogelijks nog niet helemaal kan doorgronden - de radicalen - óf je ziet ze als een straf of interventie van God de reactionairen. De gematigde verlichting schippert tussen die twee, schrijft sommige aspecten aan God toe, andere aan de natuur, net zoals ze de samenleving wil verbeteren maar toch niet haar structuren wil veranderen. Dat is een onmogelijke positie die uiteindelijk terugvalt, leidt tot of samenvalt met het behoud. Ik ben het totaal niet eens met Philipp Blom als hij beweert dat Hume een radicale verlichte denker is. Hume is reactionair. En je kunt dit doortrekken vanavond zal ik dat ook doen in de discussie met Blom - er ontbreekt bij hem (Hume, maar ook Blom) een politieke dimensie. Het epicurisme zoals van Lucretius waar Blom de nadruk op legt en dat inderdaad zijn belang heeft voor Spinoza, is een individuele geluksfilosofie die de politiek of religie niet uitdaagt doch juist vereist dat men afziet van de maatschappij. Dit is iets totaal anders dan wat in de radicale verlichting gebeurt, iets totaal anders dan wat Spinoza probeert duidelijk te maken. Spinoza is revolutionair omdat zijn ideeën slaan op politiek en maatschappij. Spinoza is subversief in de zin dat hij de publieke sfeer en wetten probeert te veranderen.

\section{Noten}

1 Aldus Israel J. in: In strijd met Spinoza. Het failliet van de Nederlandse Verlichting (1670-1800), Amsterdam, Bert Bakker, 2007, p. 5.

2 Israel J., Democratic Enlightenment. Philosophy, Revolution, and Human Rights 17501790, Oxford, Oxford University Press, 2011.

3 Israel J., Radical Enlighentment. Philosophy and the Making of Modernity 1650-1750, Oxford, Oxford University Press, 2001.

4 Raynal, Diderot, Deleyre, et cetera., Histoire philosophique et politique des établissements et du commerce des Européens dans les deux Indes (6 vols., Amsterdam, 1770): Israel J., 2011, p. 964.

5 Maria José Villaverde, 'Rousseau, lecteur de Spinoza', SVEC 369 (1999), pp. 107-139: Israel J., 201 1, pp. 1025.

6 Israel J., 2011 , pp. 873-882. 
7 Margaret Jacobs publiceerde in 1981 The Radical Enlightenment en lanceerde dus als eerste de idee van twee soorten verlichting, een radicale van libertijnse vrijdenkers, en een hoge, filosofische die Israel 'gematigd' zal noemen. Israel neemt het onderscheid en de terminologie over in zijn Radical Enlightenment van 2001 (en in de twee andere delen van de trilogie plus in de kleinere werken die hij ondertussen publiceerde) maar het is zijn verdienste de stelling dat de radicale vrijdenkers teruggaan op het werk van Spinoza en van denkers in diens omgeving met een overvloed aan materiaal te hebben onderbouwd. 8 In hoofdstuk 2, het eerste na de inleiding, 'Nature and Providence: Earthquakes and the Human Condition', maakt Israel het verschil tussen gematigde en radicale verlichting duidelijk op een directe en beeldrijke manier door een bespreking van de grote aardbeving-controverse van 1750-57: Israel J., 2011, pp. 39-55. 